\title{
ANALISIS DAMPAK KARAKTERISTIK KEPRIBADIAN DAN GAYA KEPEMIMPINAN OTOKRATIS TERHADAP KINERJA KARYAWAN PADA ATTEENA HIJAB JOMBANG
}

\author{
Anggie Ayundea Firmana \\ Department of Management FEB UMM \\ E-mail: anggie.ayundea@gmail.com
}

\begin{abstract}
The purpose of this study is, to describe the characteristics of personality, autocratic leadership, and the performance of the employee. The next is, to know whether the significantly characteristics of the personality can influence performance of the employee. The third, to know the significantly of the leadership to influence on employee performance. Furthermore to determine whether the characteristics of the personality and autocratic leadership on the employee performance. Fifth, to know among the characteristics of personality and the autocratic of leadership form that contribute of the largest influence on performance of the employee. The population of all employees, total sample 41 and the sampling technique of total sampling. The writer used the technique of collecting data is questionnaires and documentation. In this research the analytical tool using a range of scales and multiple linier analysis. The result of the analysis part of the scale characteristics of the personality included the criteria is quite good, the autocratic leadership included the criteria is fairly strong and employee performance include the criteria is quite good. The result of hypothesis testing is stating the characteristic of personality and the significant the autocratic of the leadership can influence on the employee performance. Personality characteristics are variable that have the greatest contribution to employee performance.
\end{abstract}

Keywords: personality characteristics, autocratic leadership, employee performance

\section{PENDAHULUAN}

Pada era globalisasi saat ini dengan tingkat perkembangan ekonomi dalam bisnis yang semakin maju, perubahan teknologi, serta ketatnya persaingan antar perusahaan sehingga diperlukan sumber daya manusia yang berkualitas, profesional, dan berkompeten karena sumber daya manusia sebagai komponen yang penting. Sebagaimana peran dan fungsinya sebagai penggerak dalam mencapai tujuan dan mendukung dalam keberhasilan perusahaan.

Kinerja karyawan juga memiliki peran yang sangat penting dalam pencapaian keberhasilan organisasi, karena karyawan merupakan salah satu faktor penentu keberhasilan dimana harus memiliki kinerja yang baik. Organisasi yang berhasil dalam pencapaiann tujuannya perlu mengetahui kepribadian karyawan dengan melakukan upaya yang tepat sebagai pendorong kinerja, sehingga 
diperoleh kerjasama yang baik dengan karyawan (Aprianto, 2012).

Sumber daya manusia yang tergabung dalam sebuah organisasi sebagai penggerak dan pelaksana operasional perusahaan memiliki kepribadian yang tentunya berbedabeda dari masing-masing individu. Sebuah organisasi terdiri dari individu-individu yang berbeda, masing-masing individu menunjukkan keunikan dalam teminologi kemampuan, keterampilan, kepribadian, persepsi, tindakan, nilai, dan etika (Isvandiari dan Susilo, 2014). Adapun kepribadian dapat dikatakan sebagai keseluruhan cara dimana seorang individu bereaksi dan berinteraksi dengan individu lain. Kepribadian bersifat unik dan konsisten, keunikan inilah yang menunjukkan identitas diri atau gambaran diri dimana tiap individu berbeda-beda (Robbins dan Judge, 2008).

Individu yang tergabung dalam sebuah organisasi memiliki karakter kepribadian tertentu yang sudah melekat dan mempengaruhi perilaku ditempat kerja. Perbedaan karakter tiap karyawan diharapkan organisasi memahami dan dapat menempatkan pada pekerjaan yang sesuai. Seorang manajer harus dapat mengenali kepribadian setiap karyawannya, agar dapat tercapainya suatu kinerja sehingga dapat tercapainya tujuan perusahaan. Namun banyak manajer yang tidak mengetahui kepribadian karyawannya sehingga dapat merugikan organisasi, contohnya tidak disiplinnya kerja, kelalaian kerja, dan kecelakaan kerja.

Kinerja karyawan memiliki pengaruh yang besar dalam mewujudkan tujuan organisasi, karena berhasil dan sukses tidaknya perusahaan dapat dilihat dari kinerja karyawannya. Kinerja karyawan dipengaruhi beberapa faktor, termasuk didalamnya karakteristik kepribadian, dan gaya kepemimpinan yang diterapkan oleh organisasi tersebut. Dalam penelitian Ena (2012) menunjukkan karakteristik kepribadian sebagai variabel yang dapat mempengaruhi kinerja karyawan.

Dalam suatu organisasi peran seorang pemimpin sangatlah penting, karena pemimpin yang akan menggerakkan dan mengarahkan dalam mencapai tujuan organisasi. Menjadi seorang pemimpin tidaklah mudah dibutuhkan pemimpin yang dapat meningkatkan semangat kerja, bijaksana, dapat mengarahkan, dan meningkatkan kinerja para bawahannya.

Perusahaan membutuhkan figur atau sosok pemimpin yang mampu menumbuhkan semangat kerja, meningkatkan kinerja, mengkoordinasi orang-orang atau karyawan dalam kelompok kerja serta mengintegrasikan mereka ke dalam situasi atau iklim kerja yang solid dan harmonis guna mencapai tujuan bersama (Putra, 2013).

Pemimpin memiliki peran yang sangat penting untuk memengaruhi perilaku orang lain terutama bawahannya untuk berfikir dan bertindak positif secara nyata. Dalam mengelola karyawan harus menciptakan suatu komunikasi kerja yang baik antara atasan dan bawahan agar tercipta hubungan kerja yang baik, harmonis, dan selaras. Interaksi yang dipengaruhi dalam berbagai kondisi antara pemimpin dengan bawahannya memengaruhi gaya 
kepemimpinannya. Dengan kata lain, dapat dikatakan bahwa keberhasilan atau kegagalan tujuan suatu organisasi ditentukan oleh kualitas pemimpin dan bagaimana gaya kepemimpinannya.

Tabel 1. Data target dan realisasi produksi

\begin{tabular}{ccccc}
\hline \multirow{2}{*}{ Tahun } & $\begin{array}{c}\text { Hari } \\
\text { Kerja }\end{array}$ & $\begin{array}{c}\text { Target } \\
\text { Produksi }\end{array}$ & Realisasi & Presentase \\
\hline 2014 & 307 & 46.050 & 52.194 & $27,94 \%$ \\
2015 & 306 & 45.900 & 37.600 & \\
\hline
\end{tabular}

Berdasarkan hasil pra riset dan wawancara penulis dengan narasumber dari Atteenahijab Jombang menemukan bahwa terdapat beberapa sifat kepribadian yang harus dimiliki oleh seorang karyawan yang memiliki sifat teliti, terbuka, kreatif, terampil, sopan santun, disiplin, tenang, dan tekun. Karyawan dengan sifat teliti, terampil, dan tekun lebih ditekankan pada bagian produksi. Sedangkan bagian pemasaran lebih ditekankan pada sifat terbuka, kreatif, dapat mendesain website, dan mengerti photoshop.

Pada bagian produksi ada karyawan yang kurang bertanggung jawab dengan tugas atau pekerjaanya. Produk yang seharusnya selesai pada hari tersebut namun diselesaikannya pada hari berikutnya. Selain itu ada karyawan yang kurang disiplin, terlambat masuk kerja.

Selain faktor kepribadian yang mempengaruhi hal ini, salah satunya juga karena penerapan gaya kepemimpinan yang kurang sesuai. Pada Atteenahijab gaya kepemimpinannya cenderung menerapkan gaya kepemimpinan otokratis. Hal ini terlihat dari struktur organisasi, dimana pemilik perusahaan sekaligus pemimpin, dan juga dalam hal pengambilan keputusan dilakukan oleh pemimpin. Selain itu berdasarkan hasil wawancara dengan kepala administrasi, menjelaskan bahwa pemimpin berperan untuk menetapkan tugas yang akan dilakukan serta dalam hal pengambilan keputusan. Adanya penerapan hukuman bagi karyawan yang terlambat masuk kerja dan pemberian imbalan atau bonus bagi karyawan yang hasil kerjanya memenuhi target yang ditetapkan.

Untuk meningkatkan kinerja karyawan diperlukan gaya kepemimpinan yang sesuai dan dapat diterima oleh karyawan, sehingga dapat memberikan dampak yang positif. Dampak positif yang dapat dirasakan oleh seluruh karyawan diharapkan menumbuhkan semangat kerja, senang, dan menciptakan iklim kerja yang harmonis untuk mencapai target yang telah ditetapkan.

Perumusan pada penelitian ini adalah bagaimana karakteristik kepribadian karyawan pada Atteenahijab Jombang? Bagaimana gaya kepemimpinan otokratis pada Atteenahijab Jombang? Bagaimana kinerja karyawan pada Atteenahijab Jombang? Apakah karakteristik kepribadian berpengaruh terhadap kinerja karyawan pada Atteenahijab Jombang? Apakah gaya kepemimpinan otokratis berpengaruh terhadap kinerja karyawan pada Atteenahijab Jombang? Apakah karakteristik kepribadian dan gaya 
kepemimpinan otokratis berpengaruh signifikan terhadap kinerja karyawan pada Atteenahijab Jombang? Diantara karakteristik kepribadian dan gaya kepemimpinan otokratis manakah yang berkontribusi terbesar pengaruhnya terhadap kinerja karyawan pada Atteenahijab Jombang?

Tujuan penelitian ini adalah ntuk untuk mengetahui pengaruh karakteristik kepribadian terhadap kinerja karyawan, gaya kepemimpinan otokratis terhadap kinerja karyawan, untuk mengetahui pengaruh antara karakteristik kepribadian dan gaya kepemimpinan otokratis terhadap kinerja karyawan, serta untuk mengetahui man diantara karakteristik kepribadian dan gaya kepemimpinan otokratis yang berkontribusi terbesar pengaruhnya terhadap kinerja karyawan pada Atteenahijab Jombang

\section{TINJAUAN PUSTAKA}

Menurut Robbins dan Judge (2008) kepribadian adalah keseluruhan cara dimana seorang individu bereaksi dan berinteraksi dengan individu lain. The Big Five Personality menurut Ivancevich, Konopaske, dan Matteson (2007) terdiri dari openness to experience (keterbukaan pada pengalaman) yaitu dimensi yang mengukur tingkat penyesuaian seseorang. Dimensi karakter ini adalah tertarik terhadap hal-hal baru, kreatif, keingintahuan, imajinatif, keyakinan yang tinggi, dan berwawasan luas.

Conscientiousness atau sifat berhati-hati. Dimensi ini mengukur tingkat kehati-hatian seseorang. Extraversion atau extraversi. Dimensi ini mengukur tingkat keterbukaan seseorang, bagaimana seseorang berinteraksi dengan orang lain. Agreeableness yaitu dimensi yang mengukur tingkat keramahan seseorang. Neuroticism atau neurotisme, biasanya disebut juga dengan emotional stability (stabilitas emosional).

Secara garis besar, ada dua faktor utama yang memengaruhi perkembangan kepribadian seseorang menurut Yusuf \& Nurihsan (2007), yakni karena faktor genetika dan lingkungan. Pada faktor genetika disebabkan oleh bawaan individu dari orang tua, dimana terbentuk dari beberapa kromoson yang didalamnya terdapat banyak sifat dan ribuan gen yang menentukan potensi dari individu tersebut. Sedangkan faktor lingkungan disebabkan oleh keluarga, kebudayaan, dan sekolah.

Kepemimpinan merupakan faktor yang sangat penting dalam suatu organisasi, karena seorang pemimpin yang mampu menggerakkan, memengaruhi orang lain, dan mengarahkan dalam mencapai tujuan organisasi. Ketika seorang individu berusaha mempengaruhi perilaku lainnya dalam suatu kelompok tanpa menggunakan bentuk paksaan, kita menggambarkan ini sebagai kepemimpinan (Robbins 2002).

$$
\text { Rivai dan Mulyadi (2010) }
$$
mengemukakan sejumlah teori kepemimpinan: yang pertama teori sifat, atas dasar asumsi bahwa seorang pemimpin yang berhasil memiliki kemampuan sendiri dibandingkan yang lain. Kemampuan tersebut yakni karakter khas yang terdiri dari karakteristik fisik, dimana hubungan antara kepemimpinan efektif dengan karakteristik fisik 
seperti usia, tinggi badan, dan penampilan. Intelegensia, pemimpin yang memiliki intelegensia (IQ) yang lebih tinggi dibandingkan dengan pengikut, sehingga seorang pemimpin dapat memengaruhi suatu anggota kelompok. Kepribadian, yang terdiri dari kesiagaan, keaslian, integritas pribadi, dan percaya diri.

Kedua, teori perilaku adalah kepemimpinan merupakan perilaku seorang individu ketika melakukan kegiatan pengarahkan suatu kelompok ke arah pencapaina tujuan. Pada studi dari University of Michigan mengidentifikasikan dua gaya kepemimpinan yang berbeda, disebut sebagai job-centered yang berorientasi pada pekerjaan dan employee-centered yang berorientasi pada karyawan.

Pada studi dari Ohio State University, program penelitian kepemimpinan ini mengahasilkan perkembangan teori dua variabel kepemimpinan, yaitu pertama membentuk struktur, dengan melibatkan perilaku dimana pemimpin mengorganisasikan dan mendefinisikan hubungan-hubungan di dalam kelompok, cenderung membangun pola dan saluran komunikasi yang jelas, dan menjelaskan cara-cara mengerjakan tugas yang benar. Pemimpin yang memiliki kecenderungan membentuk struktur yang tinggi, akan berorientasi pada tujuan dan hasil.

Kedua, konsiderasi, dengan melibatkan perilaku yang menunjukkan persahabatan, saling percaya, menghargai, kehangatan, dan komunikasi antara pemimpin dan pengikutnya. Pemimpin yang memiliki konsiderasi yang tinggi menekankan

pentingnya komunikaasi yang terbuka dan partisipasi. Ketiga, teori situasional adalah suatu pendekatan terhadap kepemimpinan yang menyatakan bahwa pemimpin memahami perilakunya, sifat-sifat bawahannya, dan situasi sebelum menggunakan suatu gaya kepemimpinan tertentu.

Gaya kepemimpinan yang dimiliki setiap pemimpin pasti berbeda, mereka memiliki style yang menjadi 5 aria khas dalam kepemimpinannya. Gaya kepemimpan menurut Nawawi (2003) diartikan sebagai perilaku atau cara yang dipilih dan dipergunakan pemimpin dalam mempengaruhi pikiran, perasaan, sikap dan perilaku para anggota organisasi atau bawahannya.

Menurut Ralph dan Ronald yang dikutip oleh (Winardi, 2000) gaya pokok kepemimpinan dibagi menjadi tiga macam, yakni gaya kepemimpinan otokratis atau otoriter, demokratis, dan bebas (laissez faire). Gaya Kepemimpinan Otokratis adalah gaya kepemimpinan dimana pimpinan banyak mempengaruhi atau menentukan perilaku para bawahannya (Winardi, 2000).

Gaya kepemimpinan demokratis yang menempatkan manusia sebagai faktor utama dan penting dalam organisasi, dalam setiap pengambilan keputusan sangat mementingkan musyawarah juga menerima masukan-masukan dari bawahan, dan keputusan akhir terletak pada bawahan. Sedangkan gaya kepemimpinan kendali bebas dimana pemimpin sebagai simbol. Kepemimpinan yang dijalankan dengan memberikan kebebasan penuh pada orang yang dipimpin dalam mengambil keputusan dan 
melakukan kegiatan menurut kehendak dan kepentingan masingmasing, baik secara perorangan maupun kelompok-kelompok kecil (Rivai dan Mulyadi, 2010).

Kinerja biasanya dilakukan pada karyawan yang bekerja pada sebuah perusahaan untuk digunakan sebagai dasar penilaian. Lebih tegas lagi Stolovitch dan Keeps (Rivai, 2011) kinerja merupakan seperangkat hasil yang dicapai dan merujuk pada tindakan pencapaian serta pelaksanaan sesuatu pekerjaan yang diminta.

Ada beberapa faktor yang memengaruhi kinerja, menurut Simamora dalam Mangkunegara (2006) yaitu faktor individual yang terdiri kemampuan dan keahlian, latar belakang, dan demografi. Selanjutnya faktor psikologis terdiri dari persepsi, sikap (attitude), personality, pembelajaran, dan motivasi. Terakhir faktor organisasi yang terdiri dari sumber daya, kepemimpinan, penghargaan, struktur, dan job design.

$$
\text { Menurut Dharma }
$$

menyatakan tiga aspek dari kinerja sebagai pengukuran suatu pekerjaan melalui kuantitas atau jumlah yang harus diselesaikan dalam pekerjaan. Kualitas atau mutu pekerjaan, tingkat ketelitian, dan tingkat kerapian yang idhasilkan oleh karyawan yang dituntut perusahaan. Dan ketepatan waktu, karyawan harus bekerja sesuai dengan target yang telah direncanakan, kinerja karyawan dilihat apakah sesuai atau tidak dengan waktu yang telah direncanakan. Kerangka pikir penelitian ini sebagai berikut.

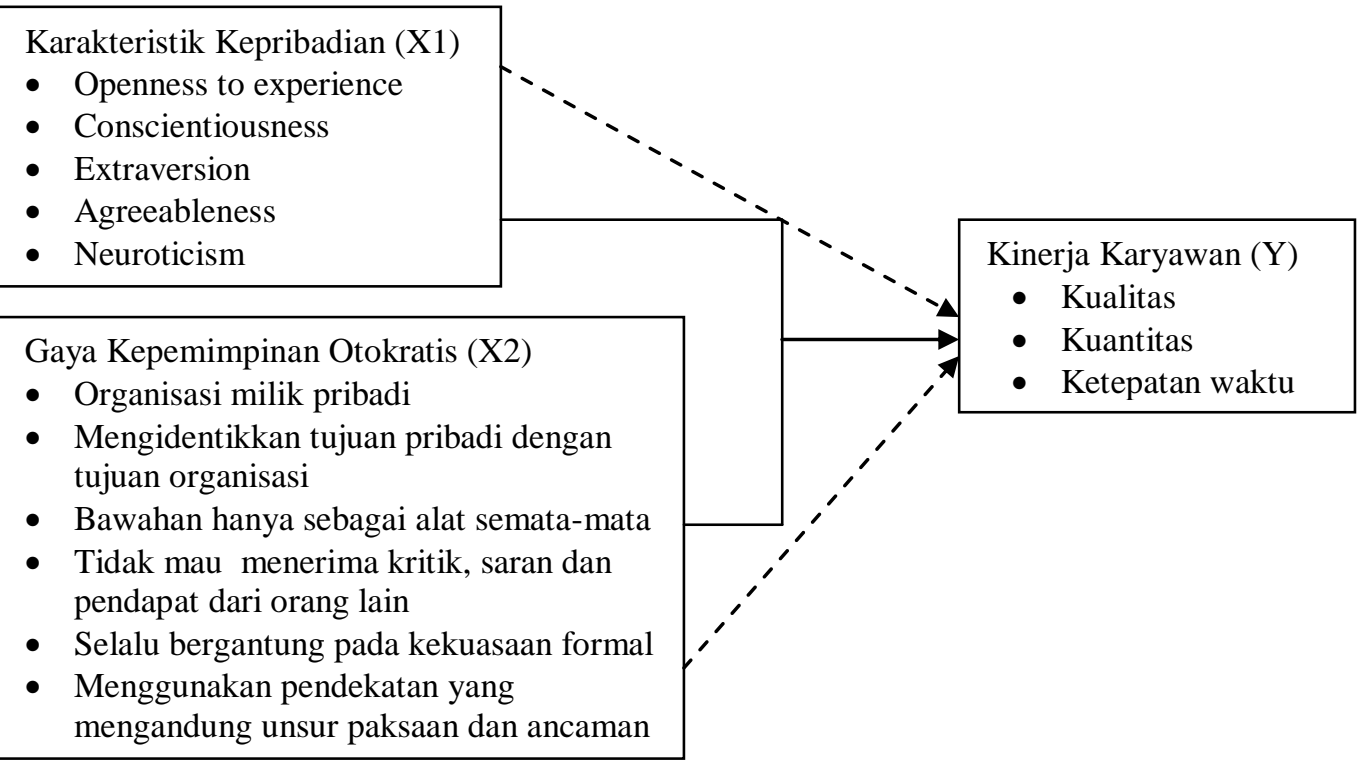

Gambar 1. Kerangka Pikir

\section{METODE PENELITIAN}

Penelitian ini dilaksanakan di Atteenahijab Jombang yang berlokasi di Jalan Sisingamangaraja No 29, Desa Kepatihan, Kecamatan
Jombang, Kabupaten Jombang, Provinsi Jawa Timur 61417. Jenis penelitian yang dilakukan adalah penelitian survey. Sumber data yang diperoleh langsung dari perusahaan 
meliputi data primer dan sekunder yang menjadi obyek penelitian.

Populasi yang digunakan dalam penelitian ini adalah karyawan Atteenahijab Jombang yang berjumlah 50 orang dan teknik yang digunakan dalam penelitian ini adalah total sampling, yaitu dengan mengambil keseluruhan total karyawan bagian produksi. Teknik analisis data yang digunakan adalah analisis regresi linier berganda, analisis rentang skala, uji pengaruh :
Uji F, Uji t dan Uji Kontribusi terbesar.

\section{HASIL DAN PEMBAHASAN}

Dalam bagian ini disajikan hasil analisis regresi linier berganda (multiple regression) variabel karakteristik kepribadian dan gaya kepemimpinan otokratis terhadap kinerja karyawan dengan hasil penelitian yang telah diolah dengan program SPSS secara parsial dan simultan.

Tabel 2. Hasil Analisis Regresi Linier Berganda

\begin{tabular}{llccc}
\hline \multicolumn{1}{c}{$\begin{array}{c}\text { Variabel } \\
\text { Dependen }\end{array}$} & \multicolumn{1}{c}{ Variabel Independen } & $\begin{array}{c}\text { Unstandartzed } \\
\text { Coefficients }\end{array}$ & $\mathrm{t}_{\text {hitung }}$ & Sig. \\
\hline \multirow{1}{*}{ Kinerja } & Karakteristik Kepribadian & 0,308 & 5,873 & 0,000 \\
& $\begin{array}{l}\text { Gaya Kepemimpinan } \\
\text { Otokratis }\end{array}$ & $-0,298$ & $-6,233$ & 0,000 \\
\hline Konstanta & $: 5,688$ & & & \\
$\mathrm{R}$ & $: 0,821$ & & & \\
R square & $: 0,674$ & & & \\
Adjusted R square & $: 0,657$ & & \\
$\mathrm{~F}$ & $: 39,292$ & & \\
\hline
\end{tabular}

Dari Tabel 2. Didapatkan persamaan regresi yaitu, $\mathrm{Y}=5,688+0,308 \mathrm{X}_{1}+$ - 0,298 $X_{2}+\varepsilon$. Konstanta sebesar positif 5,688 mengindikasikan karakteristik kepribadian dan gaya kepemimpinan otokratis memiliki pengaruh terhadap kinerja karyawan pada Atteenahijab Jombang.

Koefisien regresi karakteristik kepribadian $\left(\mathrm{X}_{1}\right)$ sebesar positif $(0,308)$, mengindikasikan bahwa jika karakteristik kepribadian mengalami peningkatan maka kinerja karyawan juga akan mengalami peningkatan. Dapat diartikan jika makin baik karakteristik kepribadian seseorang yang meliputi Openness to experience (terbuka pada hal-hal baru), Conscientiousness (sifat berhati-hati), Extraversion (extraversi), Agreeableness (ramah) dan Neuroticism (stabilitas emosional) maka kinerja karyawan yang ditinjau dari kualitas, kuantitas dan ketepatan waktu juga akan semakin meningkat.

Koefisien regresi gaya kepemimpinan otokratis sebesar negatif $-0,298$, mengindikasikan jika gaya kepemimpinan otokratis mengalami peningkatan maka kinerja karyawan akan mengalami penurunan. Dapat diartikan jika gaya kepemimpinan yang diterapkan makin otokratis maka kinerja karyawan akan semakin menurun. 
Tabel 3. Hasil Koefisien Korelasi Determinasi

\begin{tabular}{ccccc}
\hline Model & $\mathrm{R}$ & $\mathrm{R}$ & $\begin{array}{c}\text { Adjusted } \\
\text { square }\end{array}$ & $\begin{array}{c}\text { Std, Error } \\
\text { of the } \\
\text { Estimate }\end{array}$ \\
\hline 1 & .8821 & .674 & .657 & 1.96252 \\
\hline
\end{tabular}

Berdasarkan hasil analisis dapat diperoleh hasil $\mathrm{R}^{2}$ (koefisien determinasi) sebesar 0,674. Berarti bahwa keragaman variable dependen yaitu kinerja karyawan dapat dijelaskan oleh variable independen yaitu karakteristik kepribadian dan gaya kepemimpinan otokratis sebesar 0,674. Dengan kata lain kontribusi karakteristik kepribadian $\left(\mathrm{X}_{1}\right)$ dan gaya kepemimpinan otokratis $\left(\mathrm{X}_{2}\right)$ terhadap kinerja yaitu sebesar $67,4 \%$, sedangkan sisanya sebesar $32,6 \%$ merupakan kontribusi dari variable lain yang tidak dibahas dalam penelitian ini.

Tabel 4. Hasil Uji t Karakteristik Kepribadian

\begin{tabular}{lcccc}
\hline \multicolumn{1}{c}{ Variabel } & Nilai $_{\text {hitung }}$ & Nilai $t_{\text {tabel }}$ & Sig. & Keterangan \\
\hline $\begin{array}{l}\text { Karakteristik kepribadian } \\
\left(\mathrm{X}_{1}\right)\end{array}$ & 5,873 & 2,024 & 0,000 & Signifikan \\
\hline
\end{tabular}

Dari hasil uji t pada tabel diatas dapat diketahui jika nilai thitung yang dihasilkan 5,873 lebih besar dari nilai ttabel 2,024 karena nilai thitung lebih besar dari nilai ttabel dan nilai signifikan yang dihasilkan $(0,000)$ dibawah $0,05 \quad(\alpha)$ maka keputusan yang diambil adalah menolak H0 sehingga dapat dikatakan bahwa variabel karakteristik kepribadian (X1) berpengaruh signifikan secara parsial terhadap kinerja karyawan (Y). Dengan demikian hipotesis pertama dapat diterima atau dibuktikan kebenarannya.

Tabel 5. Hasil Uji t Gaya Kepemimpinan Otokratis

\begin{tabular}{ccccc}
\hline Variabel & Nilai t $_{\text {hitung }}$ & Nilai $_{\text {tabel }}$ & Sig. & Keterangan \\
\hline $\begin{array}{c}\text { Gaya kepemimpinan } \\
\text { otokratis }\left(\mathrm{X}_{2}\right)\end{array}$ & $-6,233$ & 2,024 & 0,000 & Signifikan \\
\hline
\end{tabular}

Dari hasil uji t pada tabel diatas dapat diketahui jika nilai $t_{\text {hitung }}$ yang dihasilkan -6,233 lebih besar dari nilai $t_{\text {tabel }}=2,024$ karena nilai $t_{\text {hitung }}$ lebih besar dari nilai $t_{\text {tabel }}$ dan nilai signifikan yang dihasilkan 0,000 dibawah $0,05(\alpha)$ sehingga dapat dikatakan bahwa variabel gaya kepemimpinan otokratis $\left(\mathrm{X}_{2}\right)$ berpengaruh signifikan secara parsial terhadap kinerja karyawan (Y). Dengan demikian hipotesis kedua dapat diterima atau dibuktikan kebenarannya.

Tabel 6. Hasil Uji F Karakteristik Kepribadian dan Gaya Kepemimpinan Otokratis Berpengaruh Signifikan Terhadap Kinierja Karyawan

\begin{tabular}{ccccc}
\hline Variabel & $\begin{array}{c}\text { Nilai } \\
\mathrm{f}_{\text {hitung }}\end{array}$ & Nilai $\mathrm{f}_{\text {tabel }}$ & Sig. & Keterangan \\
\hline $\begin{array}{l}\text { Karakteristik Kepribadian }\left(\mathrm{X}_{1}\right) \text { dan } \\
\text { Gaya kepemimpinan otokratis }\left(\mathrm{X}_{2}\right)\end{array}$ & 39,292 & 3,245 & 0,000 & $\begin{array}{l}\text { Positif dan } \\
\text { Signifikan }\end{array}$ \\
\hline
\end{tabular}


Berdasarkan hasil analisis regresi berganda pada 9aria diperoleh nilai $F_{\text {hitung }}$ sebesar 39,292 dengan tingkat signifikansi sebesar 0,000. Dari perhitungan $F_{\text {tabel }}$ yang sudah dilakukan, nilai $F_{\text {tabel }}$ diperoleh sebesar 3,245. Yang berarti sehingga dapat diartikan karakteristik kepribadian $\left(\mathrm{X}_{1}\right)$ dan gaya kepemimpinan otokratis $\left(\mathrm{X}_{2}\right)$ secara bersama-sama mempunyai pengaruh yang signifikan terhadap kinerja karyawan (Y). Dengan demikian hipotesis ketiga dapat diterima atau dibuktikan kebenarannya.

Tabel 7. Hasil Pengujian Kontribusi Terbesar

\begin{tabular}{lc}
\hline \multicolumn{1}{c}{ Variabel } & Unstandartzed Coefficients \\
\hline Karakteristik Kepribadian $\left(\mathrm{X}_{1}\right)$ & 0,308 \\
Gaya Kepemimpinan Otokratis $\left(\mathrm{X}_{2}\right)$ & $-0,298$ \\
\hline
\end{tabular}

Berdasarkan tabel diatas menunjukkan bahwa koefisien regresi 9 ariable karakteristik kepribadian 0,308 lebih besar dari nilai koefisien regresi gaya kepemimpinan otokratis -0,298. Dari hasil tersebut dapat disimpulkan bahwa karakteristik kepribadian mempunyai pengaruh terbesar terhadap kinerja karyawan, maka hipotesis dapat diterima atau dibuktikan kebenarannya

\section{SIMPULAN}

Karakteristik kepribadian karyawan termasuk dalam kriteria cukup tinggi, gaya kepemimpinan otokratis terrmasuk dalam kriteria cukup otokratis, dan kinerja karyawan termasuk dalam kriteria cukup baik. Karakteristik kepribadian yang terdiri dari openness to experience, Conscientiousness, Extraversion, Agreeableness, dan Neuroticism berpengaruh signifikan terhadap kinerja karyawan. Gaya kepemimpinan otokratis berpengaruh negatif signifikan terhadap kinerja karyawan. Karakteristik kepribadian dan gaya kepemimpinan otokratis secara simultan berpengaruh signifikan terhadap kinerja karyawan. Karakteristik kepribadian mempunyai kontribusi terbesar pengaruhnya terhadap kinerja karyawan.

Saran yang dapat diberikan pada Atteenahijab Jombang yaitu perusahaan diharapkan dapat lebih meningkatkan kepribadian dari karyawan melalui pelatihan kepribadian. Perusahaan juga diharapkan dapat lebih lebih mendengarkan pendapat, kritik, dan saran dari karyawan agar karyawan merasa dapat menyalurkan ide, pendapat, kreativitasnya untuk kepentingan perusahaan dalam pencapaian tujuan perusahaan yang juga berdampak pada hubungan pemimpin dengan bawahan semakin baik, dan juga diharapkan dapat lebih meningkatkan kinerja karyawan melalui pelatihan dan pengembangan berkelanjutan kepada seluruh karyawan maka kinerja karyawan akan menjadi semakin lebih baik.

\section{DAFTAR PUSTAKA}

Aprianto, Didik. 2012. "Pengaruh Tipe Kepribadian Terhadap Kinerja Pada Perusahaan Roti Mandiri Wonogiri”. 
Universitas Muhammadiyah Malang.

Dharma, Agus. 1991. Manajemen Prestasi Kerja. Jakarta: CV. Rajawali.

Ena, Zet. 2012. “Analisis Pengaruh Karakteristik Kepribadian. Budaya Organisasi, dan Kualitas Kehidupan Kerja Terhadap Kepuasan Kerja dan Kinerja Karyawan Pada Rosalia Indah Group”. Universitas Diponegoro.

Hasibuan, Malayu. 2001. Manajemen Sumber Daya Manusia: Pengertian Dasar, Pengertian, dan Masalah. Jakarta: PT. Toko Gunung Agung

Isvandiari dan Susilo. 2014. "Pengaruh Kepribadian dan Disiplin Kerja Terhadao Kinerja Karyawan Dinas Luar Asuransi Jiwa Bersama Bumi Putera 1912 cabang Dieng Malang”. STIE AsiA Malang Invancevich, John M., Konopaske Robert., dan Matteson Michael T. 2007. "Perilaku dan Manajemen Organisasi". Edisi ketujuh. Jilid I. Jakarta:Erlangga.

Mangkunegara, Anwar Prabu. 2006. Evaluasi Kinerja Sumber Daya Manusia. Bandung: PT. Refika Aditama.

Nawawi, Hadari. 2003. Kepemimpinan Mengfektifkan
Organisasi. Yogyakarta: Gajah Mada University.

Prawira, Purwa Atmaja. 2013. Psikologi Kepribadian dengan Perspektif Baru. Yogyakarta: AR-RUZZ Media

Putra, Christian Bayu. 2013. "Pengaruh Gaya Kepemimpinan Direktif, Suportif, dan Partisipatif Terhadap Kinerja Karyawan Pada PT. Astra International Tbk. Daihatsu Malang”. Skripsi. Fakultas Ilmu Administrasi Universitas Brawijaya Malang.

Rivai dan Mulyadi. 2010. Kepemimpinan dan Perilaku Organisasi. Jakarta: PT.RajaGrafindo Persada.

Rivai, Veithzal. 2011. Performance Appraisal. Jakarta: Rawajali Press.

Robbins, S.P. 2002. Perilaku Organisasi: Konsep, Kontroversi, dan Aplikasi. Jakarta: Penerbit Erlangga.

Robbins dan Judge. 2008. Perilaku Organisasi. Jakarta: Salemba Empat .

Winardi. 2000. Kepemimpinan Dalam Manajemen, Cetakan Kedua. Jakarta. PT

Rineka Cipta.

Yusuf dan Nurihsan. 2007. Teori Kepribadian. Bandung: PT. Remaja Rosdakarya. 